Physics International 3 (1): 22-27, 2012

ISSN 1948-9803

(C) 2012 Science Publications

\title{
Structural and Dielectrical Properties of Sterilized Human Teeth
}

\author{
${ }^{1}$ Mostafa Fawzy Eissa, ${ }^{2}$ Hassan Mohamed El-Shamy and ${ }^{1}$ Hassan Saad Hanafy \\ ${ }^{1}$ Department of Physics, Faculty of Science, Beni Suef University, Beni Suef, Egypt \\ ${ }^{2}$ Department of Conservative Dental Science, \\ Faculty of Dentistry, King Abdulaziz University, Jeddah, Saudi Arabia
}

\begin{abstract}
Problem statement: This study investigated the changes in crystallinity and dielectrical properties (conductivity) that could be demonstrated in extracted human teeth (enamel and dentin) subjected to $\gamma$-radiation at the sterilization dose $(25 \mathrm{kGy})$. Approach: Twenty human third molar teeth were used in the study. Teeth were prepared so forty enamel and dentin samples were obtained. The samples were divided into two groups. The first group contains twenty samples of enamels. The second ones contains twenty samples of dentins. Each group was further subdivided into two subgroups (10 samples each), one for control while the other for irradiated samples. The X-ray Diffraction Pattern (XDR) studies for the control and irradiated enamel and dentin samples were carried out by X-ray diffractometer. In addition, the microhardness test for the present samples were investigated. Results: The crystallinity in irradiated enamel samples was better than that in dentin where the average crystallite size in enamel was larger than that in dentin. Also, it was found that the dielectrical conductivity for dentin increased with frequency after exposure to $\gamma$-radiation. Accordingly, the number and mobility of charge carriers were increased. Conclusion: Exposure of human teeth to gamma radiation at the sterilization dose decreases the hardness of both enamel and dentin.
\end{abstract}

Key words: Enamel and dentin, sterilization dose, X-ray diffraction, dielectrical properties

\section{INTRODUCTION}

Enamel is the calcified substance that covers the entire anatomic crown of the tooth and protects the dentin. Dentin is the light yellow substance that constitutes the largest portion of the tooth. Tooth enamel can be considered as a composite material consisting of $96 \%$ inorganic material and $4 \%$ organic material and water. The inorganic material is mainly composed of a calcium phosphate mostly in the form of hydroxyapatite, $\mathrm{Ca}_{10}\left(\mathrm{PO}_{4}\right)_{6}\left(\mathrm{OH}_{4}\right)_{2}$ with different crystallites. Enamel has been always observed as a non electrical conductive material; it is in fact an insulator at room temperature (Reyes-Gasgam et al., 1999). Dentin is made up of $70 \%$ inorganic materials, $20 \%$ organic materials and $10 \%$ water by weight; $90 \%$ of the organic material is collagen type 1 and the remaining $10 \%$ ground substance which includes dentine-specific proteins (Cate, 1998).

Extracted teeth are widely used in testing different restorative matrials, they are considered to be a potential biological hazard and source of bloodborne pathogens. Thus, infectious agents associated with extracted teeth need to be eliminated
(Brauer et al., 2008). Several sterilization methods including autoclaving, chemical heat or dry heat sterilization are common used. However, they might either affect the material properties of the teeth or they are unsuitable for teeth containing amalgam (DeWald, 1997).

Gamma radiation is commonly applied for the sterilization of medical devices (Ley, 1982; Dorpema, 1990) and treatment of food (Crawford and Ruff, 1996).

Sterilization using Gamma radiation is one of the commonly used methods in dental researches. Gamma radiation has been shown to sterilize non-carious extracted teeth effectively without affecting the material properties if radiation doses up to $2 \mathrm{kGy}$ are used (White et al., 1994). If carious teeth are used, higher radiation doses may be necessary and might cause alterations in material structure and properties. By ionizing radiation (gamma rays), long-lived $\mathrm{CO}_{2}^{-}$radicals are created in tooth enamel (Moens et al., 1993). The concentration of the radicals grows is proportional to the absorbed dose. Radiations like alphas, protons and heavily charged particle ions have very short range in solids. Thus they cannot deposit energy inside the oral cavity unless they get incorporated internally and thus deposit their energy.

(C) 2012 Mostafa Fawzy Eissa, Hassan Mohamed El-Shamy and Hassan Saad Hanafy. This open access article is distributed under a Creative Commons Attribution (CC-BY) 3.0 license which permits unrestricted use, distribution, and reproduction in any medium, provided the original work is properly credited. DOI: 10.3844/pisp.2012.22.27 
The effect of $\gamma$-irradiation on the dielectrical properties and conductivity behavior of nanowollastonite was previously reported (Kulkarni et al., 2011). It was found that, the exposure to $\gamma$-radiation results in substantial modification in the properties of the ceramic powder due to changes in the porosity of the material. Also, the dielectrical constant increases with ion fluences for the Makrofol-KG polycarbonate induced by $100 \mathrm{MeV} \mathrm{Si}{ }^{8+}$ ions (Kumar et al., 2010).

The present study investigated the changes in structural and dielectrical properties of extracted human teeth (enamel and dentin) subjected to $\gamma$-radiation at the sterilization dose (25 kGy).

\section{MATERIALS AND METHODS}

Twenty intact, recently extracted human third molars from subjects of an average age of 18-35 years old were selected for this study. Adequate care was taken to avoid fracture of the teeth during extraction procedures. Immediately after extraction, the teeth were cleaned from blood, debris, soft tissue and calculus using ultrasonic scaler. The teeth were examined under magnifying lenses $(\times 2.5)$ and dental unit light to detect any cracks or defects in order to be discarded. The teeth were stored in distilled water (changed periodically every one week) no more than a month after extraction.

The selected teeth were mounted vertically in acrylic resin blocks, then enamel and dentin samples were prepared from the buccal and lingual surface of each tooth (twenty teeth $=$ forty samples) mesio-distally with low speed micro-slicing machine (Isomet saw Buehler, Lake Bluff, IL, USA) under constant water cooling in order to get a sample of $1.5 \mathrm{~mm}$ thick and $4 \mathrm{~mm}$ in length. The external sample was for enamel, while the inner samples for dentin samples.

Specimens grouping: The forty samples were divided into two main groups (20 each) according to tooth substrate, group 1 for enamel samples and group 2 for dentin samples. Each main group was further subdivided into two subgroups (10 each), one for the control group while the other for the irradiated samples.

Irradiation process: Each subgroup of teeth (except for the control group) was irradiated using gamma radiation from a ${ }^{60} \mathrm{Co}$ source for 5 hours to get an exposure dose of $25 \mathrm{kGy}$ for each sample. This dose was taken as sterilization dose.

Structural studies: The X-ray Diffraction Pattern (XDR) studies for the control and irradiated enamel and dentin samples were carried out by X-ray diffractometer for wide range of Bragg angle $2 \theta\left(4 \leq \theta \leq 60^{\circ}\right)$.

Dielectrical properties measurements: The dielectrical constant $\varepsilon$ ', dielectrical loss properties $\varepsilon$ " and a.c conductivity $\sigma$ of dentin group are calculated using Eq. 13 . The capacitance "C" and the loss factor $(\tan \delta$ ) were measured using Instek LCR-819 meter at frequency range $12 \mathrm{~Hz}-100 \mathrm{kHz}$ with $0.05 \%$ measurement accuracy.

The values of the dielectrical constant were determined using standard geometry techniques for a parallel plate capacitor as in Eq. 1:

$\varepsilon^{\prime}=\frac{\mathrm{Cd}}{\varepsilon_{0} \mathrm{~A}}$

where, $\varepsilon_{\mathrm{o}}$ is the permittivity of vacuum, A is the area of the sample and $d$ is the sample thickness.

The dielectrical loss was calculated using Eq. 2 as:

$\varepsilon^{\prime \prime}=\varepsilon^{\prime} \tan \delta$

Also, the conductivity was calculated from Eq. 3 as the following:

$\sigma=\varepsilon^{\prime \prime} \omega \varepsilon_{\mathrm{o}}$

where, $\omega=2 \pi \mathrm{f}$ and $\mathrm{f}$ is the applied frequency.

Microhardness test: The microhardness test for the samples were studied with the help of hardness tester equipped with a Vicker's diamond pyramidal indenter having a square base and $136^{\circ}$ pyramid angle attached to a leitz microscope. The Vicker's hardness number, Hv (Everard et al., 2006) was calculated using Eq. 4:

$$
\mathrm{H}_{\mathrm{v}}=\frac{1.854 \times \mathrm{LL}}{\mathrm{d}^{2}} \mathrm{~kg} / \mathrm{mm}^{2}
$$

where, $\mathrm{L}$ is the applied load in $\mathrm{kg}$ and $\mathrm{d}$ is the average diagonal length of the indentation in $\mathrm{mm}$. Indentations at $50 \mathrm{gm}$ loads were obtained in replicate number and average Vicker's hardness number was calculated.

\section{RESULTS}

Enamel and dentin were exposed to $\gamma$-radiation at the sterilization dose $(25 \mathrm{kGy})$. The obtained data determined any structural or dielectrical properties changes.

Structural analysis: The X-ray Diffraction Patterns (XRD) of the control and irradiated enamel and dentin are shown in Fig. 1 and 2, respectively. The crystallite size (L) of the control and irradiated have been calculated using Scherrer's Eq. 5:

$$
\mathrm{b}=\frac{\mathrm{K} \lambda}{\mathrm{L} \cos \theta}
$$


Phy. Intl. 3 (1): 22-27, 2012

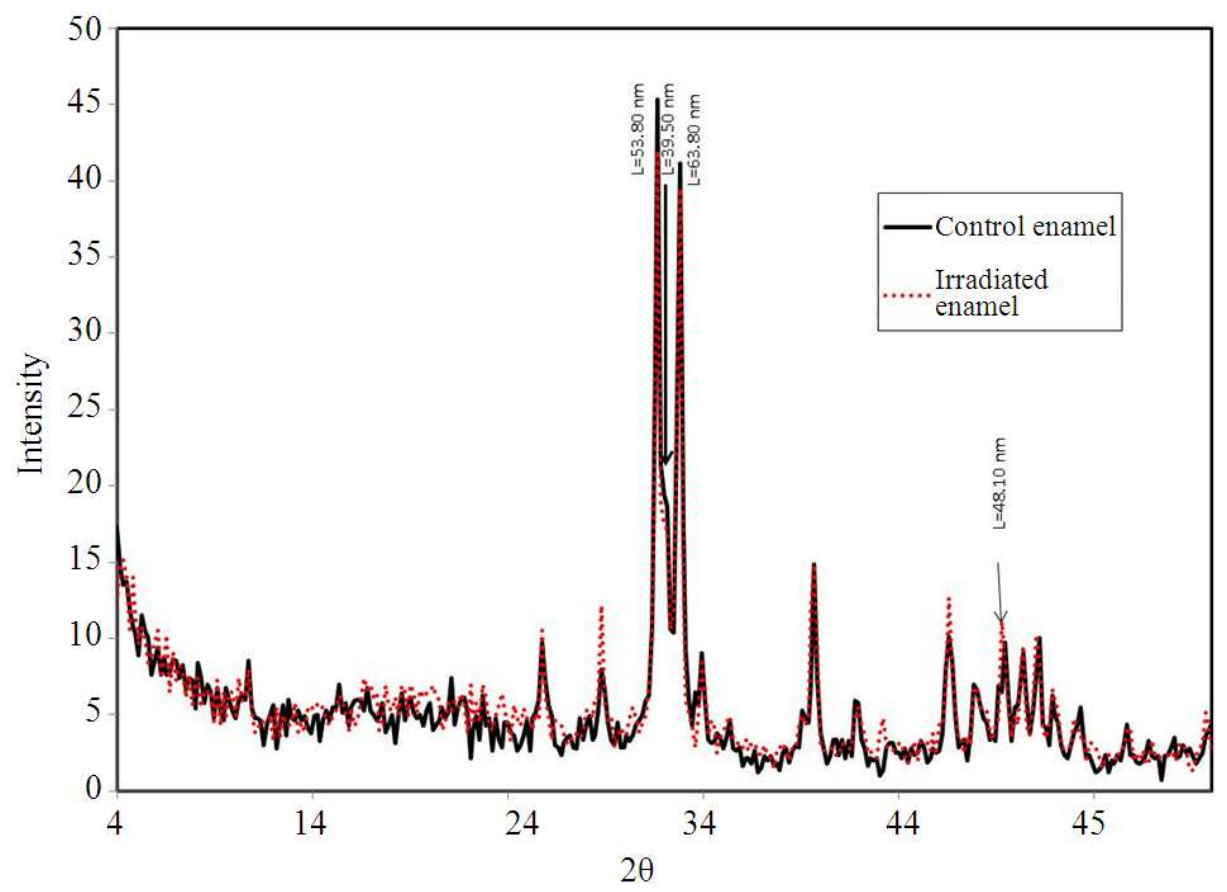

Fig. 1: X-ray diffraction pattern of control and irradiated enamel at $25 \mathrm{kGy}$ gamma ray dose; $\mathrm{L}$ is the crystallite size

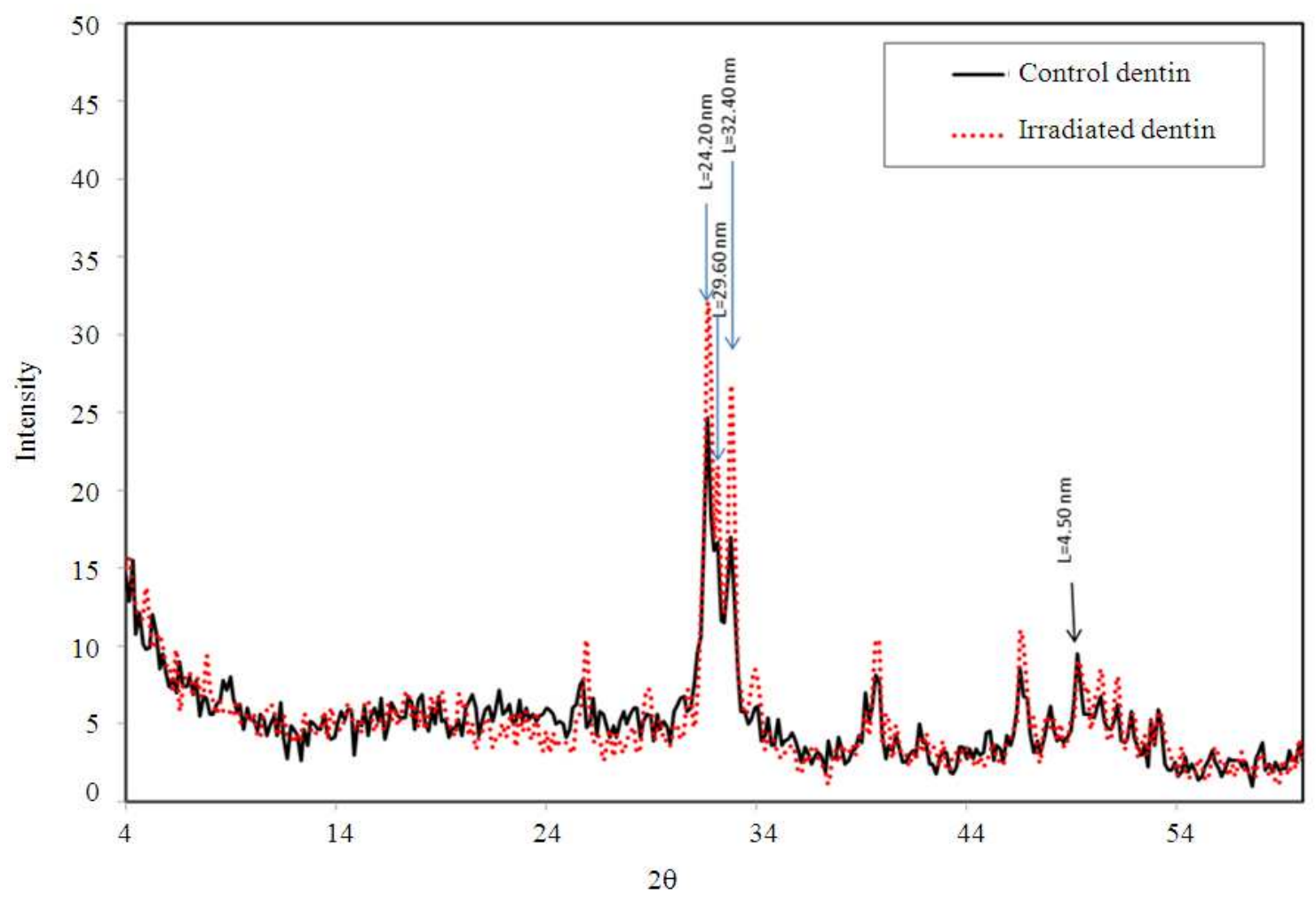

Fig. 2: X-ray diffraction pattern of control and irradiated dentin samples at $25 \mathrm{kGy}$ gamma ray dose; $\mathrm{L}$ is the crystallite size 
Phy. Intl. 3 (1): 22-27, 2012

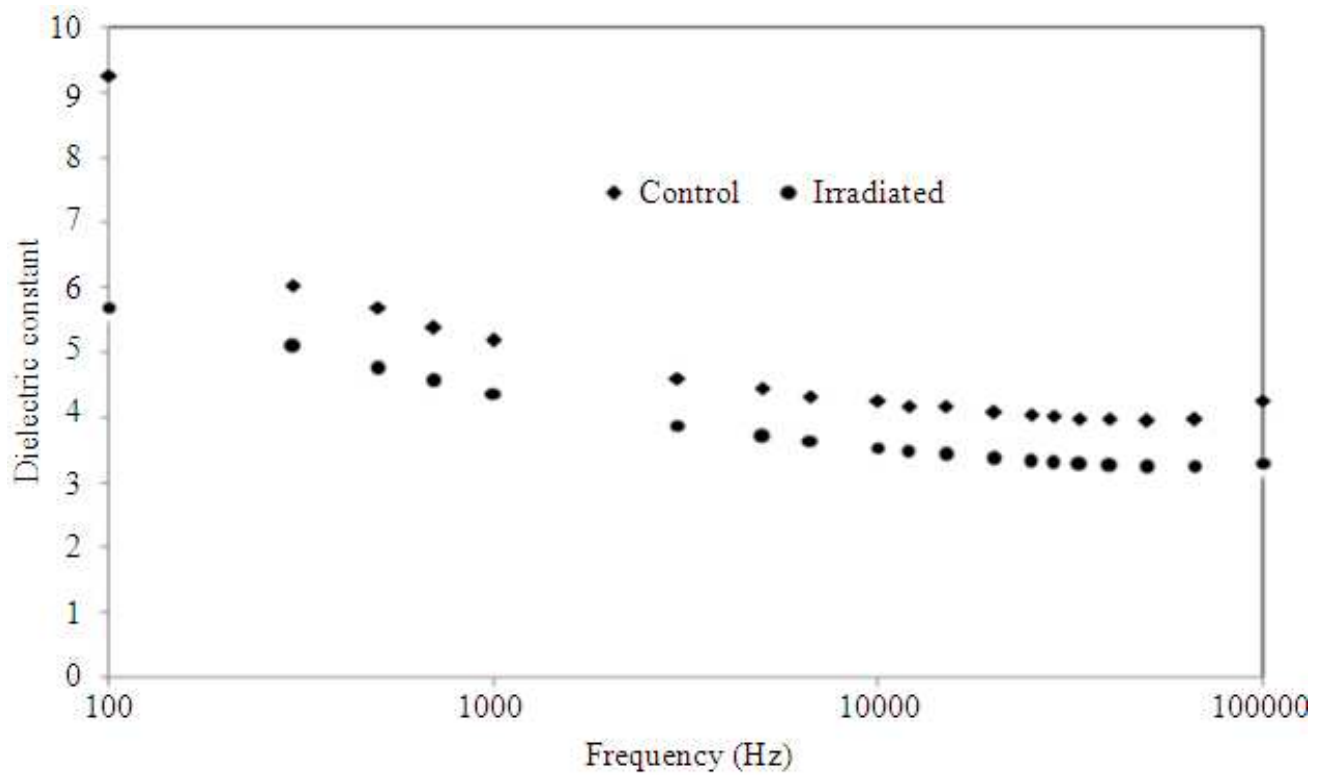

Fig. 3: The dependence of dielectrical constant on the frequency for control and irradiated dentin samples at room temperature

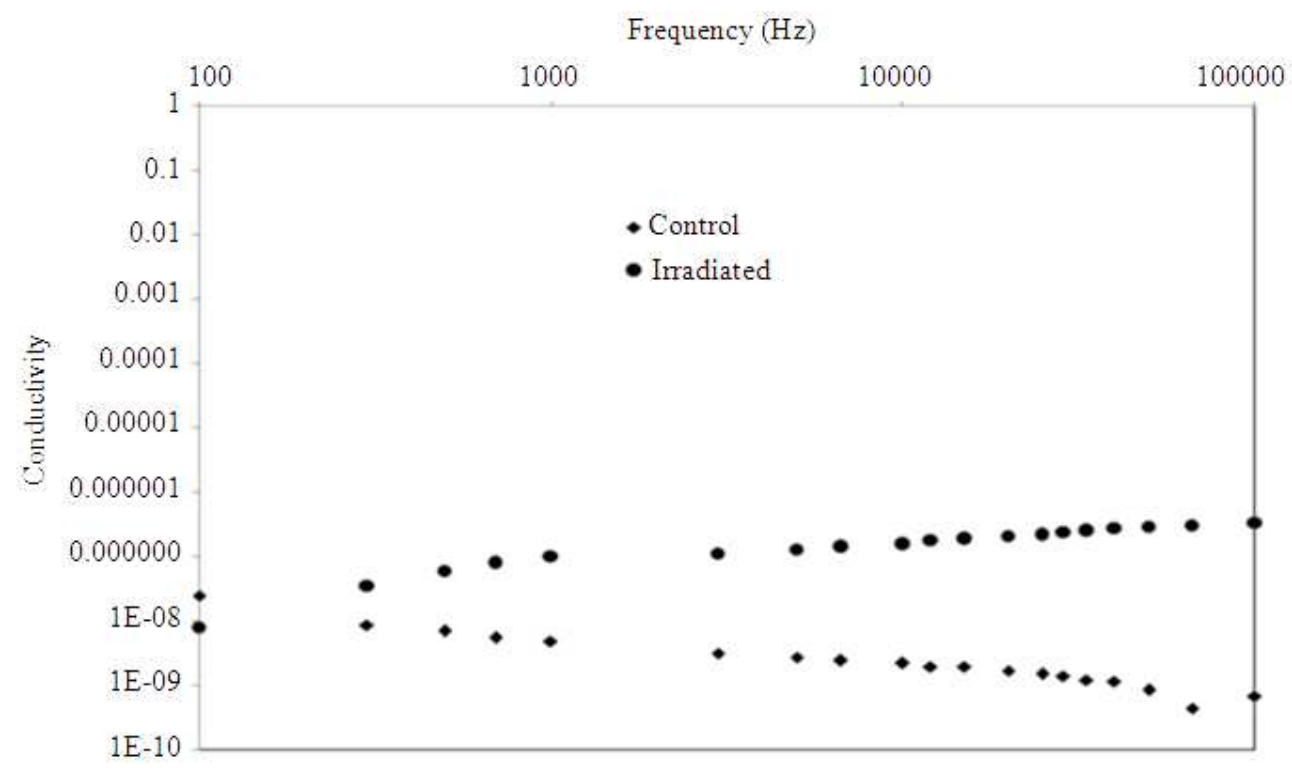

Fig. 4: The dependence of conductivity on the frequency for control and irradiated dentin samples at room temperature.

where, $b$ is the Full Width at Half Maximium (FWHM) in radians, $\lambda$ is the wavelength of $\mathrm{X}$-ray beam $\left(1.5418 \mathrm{~A}^{0}\right)$ and $\mathrm{K}$ is a constant which is assumed to be 1 .

Dielectrical properties: The dielectrical properties were investigated to confirm the XRD results. The variations of dielectrical constant and conductivity with frequency
$(0.10-100 \mathrm{kHz})$ were measured for control and irradiated dentin samples as shown in Fig. 3 and 4, respectively.

Microhardness test: The average Vicker's hardness number $\left(\mathrm{H}_{\mathrm{v}}\right)$ at indentation load of $50 \mathrm{gm}$ for control and irradiated enamel and dentin samples were presented in Table 1. 
Phy. Intl. 3 (1): 22-27, 2012

Table 1: The average surface microhardness of enamel and dentin control and irradiated samples

\begin{tabular}{lll}
\hline Groups & $\begin{array}{l}\text { Average microhardness } \\
\text { of enamel, } \mathrm{H}_{\mathrm{v}}\left(\mathrm{kg} / \mathrm{mm}^{2}\right)\end{array}$ & $\begin{array}{l}\text { Average microhardness } \\
\text { of dentin, } \mathrm{H}_{\mathrm{v}}\left(\mathrm{kg} / \mathrm{mm}^{2}\right)\end{array}$ \\
\hline Control & $340.33 \pm 19.62$ & $383.0 \pm 28.26$ \\
Irradiated & $51.00 \pm 3.77$ & $81.70 \pm 7.41$ \\
\hline
\end{tabular}

\section{DISCUSSION}

It is shown from Fig. 1 that, the most intense peaks for control and irradiated enamel samples were observed at $2 \theta=31.69,32.82,32.14$ and $49.8^{\circ}$ with lattice spacing $\mathrm{d}=2.82 \AA, 2.72 \AA, 2.78 \AA$ and $1.83 \AA$. For dentin samples the most intense peaks as shown in Fig. 2 , were at $2 \theta=31.72,50.02,32.84$ and $32.20^{\circ}$ with lattice spacing $\mathrm{d}=2.81 \AA, 1.84 \AA, 2.72 \AA$ and $2.78 \AA$. The average crystallite size was increased for control enamel from $31.25 \pm 7.40$ to $55.23 \pm 13.08 \mathrm{~nm}$ by gamma irradiation at sterilization dose ( $25 \mathrm{kGy})$. Accordingly, the XRD showed development of more crystallinity in the irradiated enamel. The average crystallite size is slightly increased by sterilization dose from $22.67 \pm 5.37 \mathrm{~nm}$ for control to $23.8 \pm 8.10 \mathrm{~nm}$ for irradiated dentin. It was found from the analysis of Xray diffraction pattern that, there is a little change in the dentin structure due to effect of sterilization dose. Also, the enamel and dentin showed monoclinic crystal lattice. The crystallinity in the enamel was better than that in the dentin. This result confirmed that, the average crystallite size in the enamel was larger than that in the dentin. Therefore, the structure of the enamel is more senestive to $\gamma$-radiation than dentin. Similar results were previously reported in the literatures (Xue et al., 2008; Vieira et al., 2003).

It is clear from the Fig. 3 that, the dielectrical constant decreased sharply with frequency up to $1 \mathrm{kHz}$ and more slowly in the higher frequency region for the control and irradiated dentin. This feature is similar to those observed in $\beta$-CaSiO3 powders (Kulkarni et al., 2011). In addition, the dielectrical constant for the irradiated samples was smaller than the control overall frequency range. Thus suggested that at low frequencies the dipoles had sufficient time to align with the applied field before changes in direction. Accordingly, the dielectrical constant will be increased. Also, if the dipoles did not have time to align before the changes in the field direction occured, the dielectrical constant will have lower value.

The decrease in dielectrical constant after exposure to the sterilization dose $(25 \mathrm{kGy})$ may cause rearrangement of atoms. The rearrangement would produce stable defects due to redistribution of $\gamma$-radiation energy over the sample. This would suppress the polarization properties and migration of defects. Accordingly, the crystallinity of the dentin will increase.
The conductivity of the control dentin samples was slightly decreased with frequency. However, its value slightly increased with frequency for dentin after exposure to $\gamma$-radiation as in Fig. 4. This could be attributed to the increase of charge carriers and its mobility which lead to increase the conductivity for the present dose. The conduction is basically due to hopping of electrons in the dielectrical materials (Kulkarni et al., 2011).

It was observed from Table 1 that, the $\mathrm{H}_{\mathrm{v}}$ values for control larger than its values for irradiated samples. The control samples had small crystallite size and showed higher hardness than irradiated ones. Therefore, the irradiated samples were degraded due to $\gamma$-radiation. This confirmed the appearance of defects in the irradiated samples with the creation of long-lived $\mathrm{CO}_{2}^{-}$-radicals (Moens et al., 1993). Accordingly, it has observed a decrease in hardness.

\section{CONCLUSION}

The changes in crystallinity and dielectrical properties in extracted human teeth (enamel and dentin) subjected to $\gamma$-radiation at the sterilization dose (25 kGy) have been investigated. The average crystallite size in the enamel was larger than that in the dentin. Therefore, crystallinity in the enamel was better than that in the dentin. In addition, it was found that the conductivity for the dentin increased with frequency after exposure to $\gamma$-radiation. Meanwhile, the number and mobility of charge carriers at the sterilization dose was increased. The present study confirmed creation of some defects in enamel and dentin resulted in sterilization. Thereby, the hardness values of enamel and dentin were decreased.

\section{REFERENCES}

Brauer, D.S., K. Saeki, J.F. Hilton, G.W. Marshall and S.J. Marshall, 2008. Effect of sterilization by gamma radiation on nano-mechanical properties of teeth. Dent. Mat., 24: 1137-1140. DOI: 10.1016/j.dental.2008.02.016

Cate, A.R.T., 1998. Oral Histology: Development, Structure and Function. 5th Edn., Mosby, St. Louis, ISBN-10: 0815129521, pp: 497.

Crawford, L.M. and E.H. Ruff, 1996 A review of the safety of cold pasteurization through irradiation. Food Control, 7: 87-97. DOI: 10.1016/09567135(96)00004-7

DeWald, J.P., 1997. The use of extracted teeth for in vitro bonding studies: A review of infection control considerations. Dent. Mater., 13: 74-81. PMID: 9467308 
Dorpema, J.W., 1990. Review and state of the art on radiation sterilization of medical devices. Int. J. Rad. Appli. Inst. Part C. Radiat. Phys. Chem., 35: 357-360. DOI: 10.1016/1359-0197(90)90118-2

Kulkarni, S., B.M. Nagabhushana, N. Parvatikar, C. Shivakumara and R. Damle, 2011. Effect of $\gamma$ irradiation on the dielectric and conductivity properties of nano-wollastonite. Mater. Sci., 2011: 808560-808566. DOI:10.5402/2011/808560

Kumar, R., P. Singh, S.A. Ali, A. Sharma and S.A. Khan et al., 2010. Swift heavy ion induced modification in makrofol-KG polycarbonate. Indian J. Pure Applied Phys., 48: 166-171.

Ley, F.J., 1982. Radiation sterilization of medical products. Int. J. Nucl. Med. Biol., 9: 165-166.

Moens, P.D.W., F.J. Callens, R.M.H. Verbeeck and D.E. Naessens, 1993. An EPR spectrum decomposition study of precipitated carbonated apatites (NCAP) dried at $25^{\circ} \mathrm{C}$ : Adsorption of molecules from the atmosphere on the apatite powders. Appl. Radiat. Isot., 44: 279-285. DOI: 10.1016/0969-8043(93)90232-Y
Reyes-Gasgam, J., G.R. Garcia, O. Alvarez-Fregoso, J.A. Chavez-Carvayar and L.E. Vargas-Ulloa, 1999. Conductivity in human tooth enamel. J. Mater. Sci., 34: 2183-2188. DOI: 10.1023/A:1004540617013

Vieira, A., R. Hancock, H. Limeback, M. Schwartz and M. Grynpas, 2003. How does fluoride concentration in the tooth affect apatite crystal size? J. Dent. Res., 82: 909-913. PMID: 14578504

White, J.M., H.E. Goodis, S.J. Marshall and G.W. Marshall, 1994. Sterilization of teeth by gamma radiation. J. Dent. Res., 73: 1560-1567. PMID: 7929992

Xue, J., L. Zhang, L. Zou, Y. Liao and J. Li et al., 2008. High-resolution X-ray microdiffraction analysis of natural teeth. J. Synchrotron Rad., 15: 235-238. DOI: 10.1107/S0909049508003397 